\title{
Investigating the Effect of Using Multiple Sensory Modes of Glossing Vocabulary Items in a Reading Text with Multimedia Annotations
}

\author{
Abbas Ali Rezaee \\ Faculty of Foreign Languages and Literatures, University of Tehran \\ 2B-9-3, Desa Airmas Condominium, Jalan Helang, 11700 Gelugor, Pulah Pinang, Malaysia \\ Tel: 61-330-26256 E-mail: aarezaee@ut.ac.ir \\ Neda Sharbaf Shoar \\ School of Educational Sciences, Universiti Sains Malaysia \\ 2C-16-03 E-Park, Jalan Batu Uban, 11700 Gelugor, Pulah Pinang, Malaysia \\ Tel: 61-750-27035Ｅ-mail: n_shoar@yahoo.com
}

Received: December 15, 2010 Accepted: December 29, 2010 doi:10.5539/elt.v4n2p25

\begin{abstract}
In recent years, improvements in technology have enhanced the possibilities of teaching and learning various subjects. This is specially the case in foreign language instruction. The use of technology and multimedia brings new opportunities for learning different areas of language. In this regard, the present study attempts to find out if the use of multimedia, images and movies, helps learners in learning vocabulary items included in a reading comprehension text. For this purpose, 70 students studying English at pre-intermediate level have been selected. These participants are then divided into three groups, each of which receives a different kind of instruction. The members of the first group were required to read some texts in which certain vocabulary items were included as the target of teaching. Those in the second group received the same texts with some pictures added so that the grasp of the unknown words would become facilitated. The students in the third group were exposed to the same material along with some movie strips. The strips were selected in a way to include the specific vocabulary items. The course duration was about 45 days. At the end of the course, all the students in the three aforementioned groups were sat for taking a vocabulary test. The test format was multiple-choice. The results of the ANOVA indicated that annotating reading comprehension passages with movie clips contributes to better learning and recall of vocabulary through reading texts.
\end{abstract}

Keywords: Annotation, Glosses, Lexical competence, Multimedia, Vocabulary assessment, Vocabulary knowledge

\section{Introduction}

The studies on the procedures of learning indicate that information is cognitively processed through visual or verbal channels (Mayer, 1997). As it is assumed by dual processing strategy (Mayer, 2003), individuals develop mental pictorial representations of graphic input and mental verbal representations of linguistic input. It is believed that the presence of both pictorial and verbal cues simultaneously can facilitate learning. This particularly happens when the corresponding visual and verbal representations are contiguously present in working memory (Mayer, 1997). Mayer's (1997) generative theory of multimedia learning states that in order to meaningfully comprehend a text in a multimedia format, learners must select relevant pictorial and/or linguistic information from it, organize the input into coherent visual and verbal mental representations, and then integrate the latter by constructing referential connections between the two.

For many years researchers have been interested in investigating the effects of pictorial and verbal indicators on learning the vocabulary of a second/foreign language (L2). This has led them to the assumption that processing supportive information, e.g. pictures or annotations, can facilitate language learning. Considering the high-imagery concrete vocabulary learning, Kellogg and Howe (1971) believe that foreign words while associated with images or actual objects are learned more easily than those without such supportive information. Terrell (1986) asserted that combining an unknown L2 word with a visual representation bypasses a direct translation and facilitates vocabulary learning. Underwood (1989, p. 19) as well notes that "we remember images better than words hence we remember words better if they are strongly associated with images". studies of other researchers propose that foreign words associated with aural or written translations and images are learned more easily than those accompanied by pictures 
or text alone (Oxford \& Crookall, 1990). For example, they suggest that the combination of pictures and text provides the grounds for accessing more parts of the brain thereby it leads to greater depth of processing than when text is processed alone. Baltova (1999) studied the effects of viewing a French video with either French audio and French subtitles or English audio and French subtitles (reversed format) on students' vocabulary learning. She found out that students learned significantly more vocabulary items when they viewed the audio-visual material with both French subtitles and French audio than in the reversed format where they viewed the video with English audio and French subtitles.

The present study, however, intends to investigate the relative efficacy of two different annotation modes in a multimedia environment: the printed text coupled with still pictures, and the printed text coupled with a dynamic video clip. This study tries to see if the presence of annotations along with reading comprehension can facilitate learning vocabulary items existing in the reading comprehension passage, and if yes, which mode of imagery, 'still picture' or 'dynamic video', is more effective in aiding vocabulary acquisition.

\section{Review of the related literature}

A dramatic progress in Information Communication Technology (ICT).has been witnessed during the last few decades. The use of technology is becoming more and more prevalent due to its amazing capability to ease everyday tasks. The new technology has challenged many taken-for-granted assumptions about human communication. It has also found its way into classrooms around the world, where it is said to enhance and facilitate learning. In terms of classroom settings, ICT brings with it certain communication patterns and, at the same time, poses the question about adaptation of classroom communicative practices.

Multimedia capabilities enhanced the potential applications of computers in foreign language education by providing audio-visual presentations and interactions tailored to the needs and interests of different individuals or groups of learners. In classroom settings involving education technology, interactions are elaborated not only by participants but also through the mediators of actions such as ICT.

According to Lee (2001), the first development of computer assisted language learning software programs can be traced back to the early 1960s, namely the Program Logic for Automated Teaching Operation (PLATO) project. This was related to the early computerized foreign language teaching systems. The improvements in the number of the software programs, language teaching/learning websites and author ware, has influenced the language teaching/learning along side with the applications of information technology.

Hanson-Smith (2002) maintains that in the 1990s the personal computer emerged as a significant tool for language teaching and learning. The extensive use of software, internet and Local Area Networks (LANs) has brought about great opportunities for learners to improve their communicative abilities, which can both be performed as individualizing practice or by connecting to a global community of learners. She argues that technology-enhanced language learning was given a huge theoretical boost when Papert (as cited in Hanson-Smith, 2002), the creator of the computer language logo, and others applied the principles devised by Dewey in 1938 and later on developed by Piaget in 1950 to the use of computers.

Within technology-assisted instruction, there are changes in both educator and student roles Willets (1992). Students feel more responsible for their own learning and teachers become a leader or an expert who assists the learners individually or in groups in using the technology based lessons, Teachers more serve as an observer and guide the students through the learning procedure. The proper use of the new technology can provide many opportunities for the language learners. This highly depends on the effective implementation of the technological instruments by teachers and educators. Willets (1992) emphasizes that neither textbooks nor technology can replace the live, unprogrammed feedback and interaction of the language teacher.

As suggested by Earp (1997), it is important to notice that while the internet based applications like the ones related to the World Wide Web are at the present time marked as being associated with teaching/learning, still non-internet technology tools can be implemented and remain as very effective tools in assisting learning. The type of media and design features that Language software for the personal computer or lab network provide for the learners is becoming more flexible and powerful. Various authoring programs are now giving the opportunity to the teachers to create their customized material for using in the classrooms and language lab systems are being improved and updated to be able to connect with the multiple media resources. Computers have also been upgraded and advanced in many ways to facilitate their incorporation with the use of software in the classroom.

Scott (1997) contends that foreign language programs coordinators have an obligation to prepare graduate teaching assistants to use technology in the classroom. Rather than focusing attention on specific computer-assisted language applications, he argues that technology can provide an opportunity for re-examining theories about foreign language 
learning. He refers to a paradigm shift that technology has brought on the foreign language teaching profession and presents a model for teacher development within the tenets of the new paradigm that uses technology to encourage enhance learning in the classroom. Moreover, Adolph and LeBlanc (1997) hold that increased expectations from higher education constituencies demand that foreign language program directors embrace new technology without option. They describe how the introduction of computer technology in one department was the result of mandates from authorities outside the department and how faculty, staff, and students responded to these mandates. According to Adolph and LeBlanc (1997), among the issues raised by the introduction of computer technology were the following: fear of technology, choice and maintenance of equipment and facilities, impact on the curriculum, and training of future faculty.

Bernhardt and kamil (1997) point out that the conceptual knowledge that the learners have at hand is much richer than the linguistic structures available to them. They explicate a use of technology targeted at realigning conceptual knowledge and new knowledge regarding cultural issues. They argue that electronic discussion groups held in English facilitate the learning of culture and thereby, enhance student affective and cognitive performance in class. Kern (1997) focuses on the growing use of local and global computer networks for language learning. He points out that computer networks potentially expand the number and diversity of people with whom language learners can communicate, and that they influence the ways in which people use language to interact with one another. They point out three social uses of computer technology - synchronous conferencing, e-mail, and MOOs (multiple user domains Object Oriented) - which present new opportunities for reorganizing classroom interaction, for extending person-to-person communication to worlds beyond the classroom, and for developing literacy and cultural literacy among foreign language learners.

\subsection{Multimedia technology types}

According to Brinton (2001), the extent to which multimedia are used in language classrooms varies depending on the methodology selected. She argues that in some methods, media have figured prominently as a force that drives the curriculum. While in other methods, media are relegated more to the design or procedure level. Brinton (2001) distinguishes between two categories of media, namely nontechnical media and technical media. She argues that the category of nontechnical media presents obvious advantages in settings where electricity is unreliable, technical resources are scare, or funding is limited. The media included in this category have also the advantage being low cost, available, accessible, and user-friendly. The media included in this category are: blackboards, whiteboards, magnet-boards, flannel-boards, pegboards, flashcards, index cards, wall charts, posters, maps, scrolls, boards games, mounted pictures, photos, cartoons, line drawings, objects, realia, pamphlets, brochures, flyers, menus, equipment operation manuals, puppets, newspapers, magazines.

Technical media are, on the other hand, costlier and less user-friendly than nontechnical media. However, they carry out with them a larger degree of 'psychological reality' in that they can bring the outside world in all its complexities into the classroom. This category of media include: record player, audiotape player/recorder, CD player/recorder, radio, television, video player/recorder, telephone, teletrainer, overhead projector, filmstrip, film projector, opaque projector, slide projector, language lab, computer lab, multimedia lab, self-access center (Brinton, 2001).

\subsection{Use of multimedia in language classroom}

Computer multimedia aided learning is considered effective in many fields including language teaching/learning. Different multimedia tools, presentations, games and other similar applications have been implemented as useful teaching/learning technique. Advances in the use of internet and networks have also made the computers popular and more frequent in use. Computers now can integrate various roles as a communication medium, a delivery medium and methodology for learning. Furthermore, educational theories support web-based instruction and provide many instructional designing guidelines (Tsou, wang, \& Tzeng, 2006).

Delaska (2002) investigates the role of multimedia in teaching Languages for Specific Purposes (LSP). He argues that both for LSP-teaching and for culture learning, media have opened up exciting ways of combining foreign language skills with specific themes and challenging subject areas. By new language learning technologies he means multimedia CALL facilities and authoring tools that permit the hypermedia integration of text, sound and video components for the presentation of learning materials and for the design of interactive learning activities.

Clearly, the potential of new language learning technologies to maximize learner flexibility and autonomy is impressive. Besides all the advances in technology there is still the challenge of the proper use of the technology in the classrooms, technology tools can only be effective if they are implemented with appropriate pedagogical considerations. The pre assumption of the implementation of computers in the classroom is that the learners are familiar with and possess the competence in the use of computers skills as part of their instructions and computers or 
other technology tools are not designed to replace the instructor in the classrooms, but that the technology assigns new roles to both learner and teacher in an increasingly collaborative learning scenario (Delaska, 2002).

\subsection{Teaching and learning vocabulary}

One of the applications of computers in the language classroom is to teach vocabulary. Kang and Dennis (as cited in Green, 2005, p. 57) write, "Any attempt to treat vocabulary learning as learning of isolated facts certainly will not promote real vocabulary knowledge". Learners require to learn vocabulary in context along with visual clues which can assist them comprehend the vocabulary meaning. Computers can provide the learners with the proper Computers can also assist learners to become autonomous and individual learners and to learn how to use various learning styles through their learning procedure.

In a study conducted by Kang and Dennis (as cited in Green, 2005), the aim was to investigate whether the use of computer can be effective in teaching vocabulary to the beginner learners of English. The study was performed in Seoul, South Korea. The fifth grade students Learning English were divided into three different groups. Each study, respectively, was using definitions, pictures, and context. The group studying definitions was provided with the English word with the definition written in Korean. This group depended mainly on rote memorization. The group studying pictures were given the definition along with a picture. The third group was provided with a situational context employing the English word first and then given the definition and picture. At the beginning, the picture and definition groups did much better than the context group. But after a few sessions, the context group's scores were much better than the other two groups. In the test given to the students at the end of the sessions as retention test the scores of the context group were significantly higher than the other two groups. Reporting Kang and Dennis's conclusion, Green (2005), says that, a period of time is required by those subjects in the context group to get used to their instructional treatment prior to getting acquainted with the type of employed instructional approach. This proved that the contextual approach was better in the long term recall of the vocabularies which was made by the use of computers more effectively and with a rich context.

Oxford (1990) points out that the English vocabulary has an extremely important role in English learning. Language learners typically have significant difficulty remembering large vocabulary items. During the recent years, many studies have focused on English learning, and most have emphasized the importance of vocabulary learning in English learning (Decarrio, 2001). It is believed that an excellent vocabulary is beneficial to inferring meaning from English sentences (Harmon, 1998 and Rupley, Logan \& Nichols, 1999), although, many learners think that memorizing English vocabulary is difficult, especially while dealing with long or infrequently used words. Research shows that low vocabulary knowledge frequently leads to the misunderstanding of the content or poor comprehension when reading English articles (Lin, 2002). Many researchers believe that facing entirely new words in an English-language article is the main obstacle in English learning (Anderson \& Freebody, 1981). Based on research in order to read English articles fluently, a learner must understand at least 2000 commonly used English words (Nation, 1990). The rich body of research indicates that vocabulary learning is central to English-language acquisition.

According to the studies done in the field, learners' lexical competence has been categorized in different ways. The distinction between receptive (understood in reading) and productive (used in writing or speech) vocabulary has been identified. Laufer and Paribakht (1998) divide learners' recognition vocabulary as passive and productive vocabulary as active. Active vocabulary is further divided into free active vocabulary, i.e., words learners themselves choose to use, and controlled active vocabulary, that is, words learners are able to use if they are required. Lexical knowledge is a continuum from a vague familiarity with a word form knowing that it exists in the language and ending with the ability to use the word correctly in free production. Henriksen (1999) suggests three dimensions of lexical competence, i.e., partial to precise knowledge, depth of knowledge, and receptive to productive use ability.

Many researchers have debated the argument about whether we should emphasize the receptive or productive knowledge of a word, even though they all recognize the complicate nature of vocabulary (Channell, 1988 and Stoller \& Grabe, 1997). Channell (1988) defines L2 vocabulary acquisition as: 1) the meaning of an L2 word can be recognized and understood both in and out of context and 2) it can be used naturally and appropriately to situation. Based on her definition, receptive knowledge precedes productive one, as acquisition of individual vocabulary comprises first comprehension, then production. However, Stoller and Grabe (1997) argue that it is too simple and general to consider the notion of 'receptive' and 'productive' of vocabulary learning.

The traditional approach for determining the usefulness of vocabulary items is finding the frequency and the range of the words in related corpora. The information from frequency studies suggests a cost benefit approach to dealing with vocabulary (Nation \& Meara, 2002). The information from frequency-based studies makes a distinction 
between high frequency words and low frequency words. The high frequency words, because of their relative importance, frequent occurrence in the texts and formation of a manageable word group should be the main concern of vocabulary teaching in the classroom. Of course, learners need to learn the low frequency words in order to be able to come up with the situation in which there is a necessary need to use or comprehend these words. The low frequency words can be learned incidentally or deliberately by the students themselves in their free time. Also, the teachers and the learners should give attention to the learners needs in order to specify the vocabulary content of the teaching materials.

Schneider, Healy, \& Bourne (2002) argue that learning vocabulary may seem like one of the easiest aspects of foreign language acquisition but is actually quite complicated, consisting of at least four interrelated component subtasks. First, the learner must acquire the ability to produce, i.e., to pronounce or to write, unfamiliar words from the foreign language (L2). Second, the learner must differentiate these unfamiliar L2 words from one another. Third, the learner must connect the unfamiliar L2 words with their familiar native language (L1) equivalents. Fourth, these new associations must be bidirectional, i.e., given the L1 word the learner must be able to produce the L2 equivalent and, conversely, given the L2 word the learner must be able to produce the L1 equivalents.

Many teachers assume that the best way for teaching vocabulary in classroom is direct teaching. However, Nation and Meara (2002) outline four strands of vocabulary learning which are a) Learning Vocabulary from meaning focused input (Listening and reading), that is, an incidental vocabulary learning for both native speakers and foreign language learners, b) Learning Vocabulary from meaning focused output (Speaking and Writing), i.e., activating passive vocabulary by the use of speaking and writing, c) Deliberate Vocabulary Learning which is the major source of vocabulary learning, as noticing and giving attention to language learning makes the learning more effective, and d) Developing Fluency with Vocabulary across the Four Skills, which includes 'the well-beaten path approach' to vocabulary learning and 'the richness approach' to fluency.

\subsection{Multimedia glosses in teaching and learning vocabulary}

Huang (2007) argues that Provision of glosses in reading can facilitate vocabulary learning by directing readers' attention towards the meaning of target words when they encounter the word forms, as long as the annotation is not intrusive. Various studies have investigated the effectiveness of multi-mode glosses over the single-mode ones, and if so, which combination of multi-mode glosses is most effective. Chun and Plass (1996) performed a series of studies on multimedia glosses and vocabulary acquisition. They figured out that the combination of text and picture glosses was more effective than text-only or text-plus -video glosses.

The relative effectiveness of multi-mode glosses over single-mode glosses was confirmed in Plass, Chun, Mayer and Leutner (1998). The study also investigated the effects of different gloss types in a multimedia context indicating whether learners are more likely to learn words when they are presented with both verbal (textual) and visual (picture) glosses or when they received one mode or none. The study found that the performance was better when the learners used both visual and verbal modes of glosses, in comparison to selecting only one mode, and finally the worst when they did not select any. The results also indicated that the combination of text and picture was better than that of text and video for learning the words.

To investigate and confirm the effectiveness of the combination of text and picture glosses over that of text and video glosses, Al-Seghayer (2001) compared the two gloss combinations. The participants were 30 students learning English as a Second Language (ESL) and they were supposed to read a 1,300-word text with 21 target vocabulary items. In doing so, seven words were glossed only with text, seven words with text and video, and the other seven with text and picture annotations; the textual cues were provided in English the students received the vocabulary tests with both recognition and production tasks. The results indicated that the combination of text and video were more effective than of the text and picture.

Ridder (2002) investigated the effect of the signaling-mode of electronic glosses in online texts, i.e., presented digitally on a computer screen, on the user's reading process, incidental vocabulary learning, and text comprehension. The findings of her study indicated that when reading a text with highlighted hyperlinks, readers are significantly more willing to consult the gloss and this does not slow down the reading process, does not affect text comprehension, and does not increase the vocabulary learned incidentally. She implies that the reading task does not seem to alter the clicking behavior of the students but seems to influence the reader's vocabulary learning, that is, a content-oriented reading task decreases the reader's attention for vocabulary.

The present study intends to find out firstly the attitudes of learners toward receiving multimedia materials while they are reading texts in language learning classrooms and secondly, the effect of the type of annotation, still images or movie clips, on their better learning of vocabulary while reading texts. 


\section{Method}

\subsection{Participants}

The participants in this study were 70 learners at the age of 22 to 30 studying English in a language institute. All of the participants were at upper-intermediate level. From the whole number of participants, 7 were females and the rest were males, all of these students had university education: 42 of them held a BA/BSc, $21 \mathrm{MA} / \mathrm{MSc}$ and $7 \mathrm{PhD}$. These 70 participants were grouped into three classes. The 23 learners in the first group were exposed to reading passages without picture annotations. The second group also consisted of 23 students and the reading passages with picture annotations were presented to them. The third group was composed of 24 students who read the passages along with watching the related movies.

\subsection{Instrumentation}

The first instrument used in this study consisted of 10 reading comprehension texts on various topics. The readability of these texts matched the level of the students. Some specific vocabulary items in these texts were selected to be emphasized during the experiment and the final test. Two versions of the same text were devised, i.e., one without any picture annotations and the other one with picture annotations. The pictures were directly related to the specific vocabulary content of the texts.

The other instrument used in this study was 10 movie clips at about 5 to 10 minutes duration. The movie clips were taken from Richards' Interchange Video Activity books and were totally related to the content of the reading comprehension passages. The students in the third group watched the movie related to each reading passage after the reading passage was presented to them.

Finally, the third instrument used in this study was the aforementioned 30-item Multiple-Choice vocabulary test including the specific vocabulary items taught by the use of the reading comprehension texts. The test was validated by two colleagues and necessary modifications were then made to the test according to the comments. The reliability coefficient of the test, shown in table 1 below, was calculated by the use of KR 21 formula. It turned out to be 0.84 .

\section{Procedure}

The design of the present study was a pre-test post-test experimental one. There was a placement test before starting the experiment for selecting students of the same level of proficiency for the experiment. After the experiment a post-test was administered to see the effect of the treatment on the participants.

The present research took about 2 months, that is, one semester, during which ten reading comprehension texts were administered to the aforementioned three classes, coded class 1,2, and 3. The kind of text administered to these three classes was different. Class 1 was exposed to reading comprehension texts without any accompanying images; class 2 was exposed to reading comprehension texts with image annotations; and class 3 was exposed to reading comprehension texts together with video clips. These ten reading comprehension texts made a part of their regular lessons besides their other class activities. At the end of the semester, a Multiple-Choice vocabulary test was administered to these three classes and it was intended to measure the vocabulary knowledge of the students in the three classes.

The study intends to investigate the relative learners' preference of two different annotation modes in a multimedia environment: the printed text coupled with still pictures, and the printed text coupled with a dynamic video clip. This study also tries to find out if the presence of annotations facilitates learning unknown vocabulary items existing in a reading comprehension passage, and if yes, which mode of imagery, 'still picture' or 'dynamic video', is more effective in aiding vocabulary acquisition. The following research questions are addressed:

What is the attitude of learners toward presenting multimedia materials together with reading comprehension texts in language classroom?

Which type of annotation, still images or movie clips, contributes to better learning of vocabulary from reading comprehension texts?

\section{Results}

\subsection{The participants' attitudes towards and preferences}

A survey was done in order to find the answer to the first research question in the present study. That is, at the end of the course and after administering the test, the students were informally interviewed. The question asked in the interview was about the type of annotation, still images or movie clips, they preferred.

As mentioned earlier, the participants in the present study were divided into three groups, each one receiving different treatments. The first group was exposed to reading comprehension texts with no picture annotation. The 
second group received reading comprehension texts with picture annotations. The last group was exposed to reading comprehension passages coupled with movie clips, that is, they watched the related movie after the introduction of reading comprehension passage. There were 23 students in each group. It is worth mentioning that the reading comprehension activity employed in this study was not the main concern of these three classes; it was, in fact, an extra activity besides their main course syllabus. All the three classes were exposed to the same reading comprehension passages. At the end of the semester, a vocabulary test was administered to all the three classes.

Compared to other groups, those students who were exposed to dynamic movie clips were more satisfied. They held that, this type of annotation leads to better, long term, and more effective learning and recalling of vocabulary items. Moreover, they maintained that watching movies after each reading comprehension text had helped them to generate a holistic view of the content of that reading text. In other words, movie clips had facilitated the process of learning the concepts of the reading comprehension passage and the process had paved the way for their better and more effective vocabulary learning.

As to the second concern of the present study, i.e., investigating the effect of the type of annotation accompanying reading comprehension texts and the contribution it might have to better learning of vocabulary items, the participants' scores in the vocabulary test were taken into account. By looking at the mean score of the participants in each annotation mode, one can conclude that the highest one belongs to movie annotation. This means that participants who were treated with this type of annotation outperformed the others in the test. Table 1 indicates the three groups of participants' performances in the vocabulary test.

As can be seen from the table, the performance of group three, the one receiving reading comprehension texts together with movie clips, was better than the other two groups. The mean score of the first group, the one receiving only reading texts, was the lowest among the all. This reveals that this group's performance on the test was the weakest.

In order to find an answer to the second research question which was about the effect of the type of annotation, i.e., word definition, still images, or movie clips, on the students' learning and recall of vocabulary items, a one-way ANOVA was run so that the comparison of the mean scores of the three groups would become possible. Table 2 indicates the results of the ANOVA run for the data collected.

As the results of the ANOVA shown in the above table indicate, the difference between the mean scores of these three groups is significant $(\mathrm{Sig}=.004, \mathrm{p}<.05)$. This can mean that, the difference is caused by the treatment rather than by chance. In other words, the types of annotation accompanied by reading comprehension texts have caused significant differences in the performances of these groups in the vocabulary test, i.e. the participants have grasped more words and have had better retention.

As Table 1 indicates, the mean score of the third group who was exposed to reading texts with movie annotation was the highest, and as Table 2, on the ANOVA for these three groups, indicates, the difference between the mean score of these three groups is significant and meaningful. Therefore, it is implied that annotating reading comprehension passages with movie clips contributes to better learning and recall of vocabulary through reading texts.

\section{Conclusion and discussion}

The result of the study indicated that the combination of video clips with text is more effective in learning vocabulary from a reading comprehension text in comparison to the combination of picture with text. Participants who were exposed to video clips and pictures learned and recalled words better than those who were provided with only a reading comprehension text without annotation. The findings also showed that movie clips were more effective than still pictures in aiding participants learning vocabulary items.

The results of this study are in line with the generative theory of multimedia learning in conjunction with cognitive load theory. This study found a general multimedia effect for vocabulary acquisition: participants who were exposed to multimedia annotations performed better in vocabulary test than those who were exposed to no annotations, a result that is in line with the dual coding assumption of dual coding theory and the generative theory of multimedia learning (Mayer, 1997; Mayer \& Moreno, 2002; and Plass, et al. 1998).

As to the interview carried out with those students who were provided with pictorial and movie clip annotations, it was found that this kind of annotation is more appealing to the learners and can result in effective and long lasting vocabulary learning. Most students liked and preferred the use of multimedia in learning vocabulary items. The third group members who received movie clips, however, showed more satisfaction.

The variety of modality cues can reinforce each other and are linked together in meaningful ways to provide an in-depth experience. Among the possible factors that may explain these results were the following: video clips better help learners build a mental image, curiosity increases concentration, and video's combination of modalities 
(dynamic image and sound) facilitate recall. These results are viewed as a starting point for further exploration into the use of video-based technology within multimedia environments.

\section{Notes on pedagogical implications}

As detailed earlier, the use of technology can enhance students' learning of vocabulary items to a large extent. Therefore, it is strongly suggested that all language classes be equipped with video projectors and computers so that the teacher would be able to get help from various forms of annotation when it comes to teaching of words appearing in reading passage. Technology, and more specifically multimedia, can be of a great instructional value to instructors, program designers and language learners by providing learner-centered instructional settings which are updated and tailored to the needs of different learners and, at the same time, assisting the teachers by giving them sufficient material that are practical and efficient. The application of technology may also enhance learning from the cognitive aspects by reducing the cognitive load burdened on the memory of learners in case technology is not implemented.

\section{References}

Adolph, W. \& LeBlanc, L. (1997). A revolution from Above: The Race for Technology in Foreign Languages. In Muyskens, J. A. (Ed), New Ways of Learning and Teaching: Focus on Technology and Foreign language Education. (Report No. FL 027910) (ERIC Document Reproduction Service No. ED482490).

Al-Seghayer, K. (2001). The Effect of Multimedia Annotation Modes on L2 Vocabulary Acquisition: A comparative Study. Language Learning and Technology, 5 (1), 202-232. Retrieved October 10, 2007, from http://lt.msu.edu/vol5num1/alseghayer/default.html.

Anderson, R. C. \& Freebody, P. (1981). Vocabulary Knowledge. In J. T. Guthrie (Ed.), Comprehension and Teaching: Research Reviews (pp. 77-117). Newark, NJ: International Reading Association.

Baltova, I. (1999). The Effect of Subtitled and Staged Video Input on the Learning and Retention of Content and Vocabulary in a Second Language. Unpublished doctoral dissertation. University of Toronto, Canada.

Bernhardt, E. \& Kamil, M. (1997). Enhancing Foreign Culture Learning Through Electronic Discussion. In Muyskens, J. A. (ed), New Ways of Learning and Teaching: Focus on technology and Foreign language Education. (Report No. FL 027910) (ERIC Document Reproduction Service No. ED482490).

Brinton, D. M. (2001). The Use of Media in Language Teaching. In Celce-Murcia, M. (Ed), Teaching English as a Second or Foreign language $\left(3^{\text {rd }}\right.$ ed.). Heinle and Heinle.

Channell, J. (1988). Psycholinguistic Considerations in the Study of L2 Vocabulary Acquisition. In R. Carter, and M. McCarthy (Eds.), Vocabulary and Language Teaching (pp. 83-96). New York: Longman.

Chun, D. M. \& Plass, J. L. (1996). Effects of Multimedia Annotations on Vocabulary Acquisition. The Modern Language Journal, 80 (2), 183-198.

Decarrio, J. S. (2001). Vocabulary Learning and Teaching. In Celce-Murcia (Ed.), Teaching English as a Second or Foreign Language ( $3^{\text {rd }}$ edition). Boston: Heinle and Heinle.

Delaska, A. (2002). Sites for Construction: Language Learning, Multimedia, and the International Engineer. Computers and Education, 39, 129 - 143.

Earp, S. (1997). More than Just the Internet: Technology for Language Teaching. (ERIC Document Reproduction Service No. ED414767). Eric Digest.

Green, T. (2005). Using Technology to Help English Language Students Develop Language Skills: A Home and School Connection. Multicultural Education. 13 (2), 56-59.

Hanson-Smith, E. (2002). Computer-Assisted Language Learning. In Carter, R. and Nunan, D. (Eds). Teaching English to Speakers of Other Languages. Cambridge University Press.

Harmon, J. M. (1998). Vocabulary Teaching and Learning in a Seventh-Grade Literature-Based Classroom. Journal of Adolescent and Adult Literacy, 41(7), 518-529.

Henriksen, B., 1999. Three Dimensions of Vocabulary Development. Studies in Second Language Acquisition 21, 303-317.

Huang, H. (2007). Vocabulary Learning in An Automated Graded Reading Program. Language Learning and Technology. 11(3), pp. 64-82. Retrieved October 10, 2007, from http://ltt.msu.edu/vol5num1/alseghayer/default.html. 
Kellogg, G. \& Howe, M. J. (1971). Using Words and Pictures in Foreign Language Learning. Alberta Journal of Educational Research, 17(2), 87-94.

Kern, R. G. (1997). Technology, Social Interaction, and FL Literacy. In Muyskens, J. A. (ed), New Ways of Learning and Teaching: Focus on Technology and Foreign Language Education. (Report No. FL 027910) (ERIC Document Reproduction Service No. ED482490).

Laufer, B. \& Paribakht, T.S. (1998). The Relationship between Passive and Active Vocabularies: Effects of Language Learning Context. Language Learning 48 (3), 365-391.

Lee, K. C. (2001). Selecting and Integrating CALL Software Programs into the EFL Classroom. (Report No. Fl 026794) (ERIC Document Reproduction Service No. ED454736).

Lin, Z. (2002). Discovering EFL Learners' Perception of Prior Knowledge and Its Role in Reading Comprehension. Journal of Research in Reading, 25(2), 172-190.

Mayer, R. E. (1997). Multimedia Learning: Are We Asking the Right Questions? Educational Psychologist, 32(1), $1-19$.

Mayer, R. E. and Moreno, R. (2002). Aids to computer-based multimedia learning. Learning and Instruction, 12, 107-110.

Nation, I. S. P. (1990). Teaching and Learning Vocabulary. New York: Newbury House.

Nation, P. \& Meara, P. (2002). Vocabulary. In N. Schmitt (Ed.), An Introduction to Applied Linguistics. Oxford University Press.

Oxford, R. (1990). Language Learning Strategies: What Every Teacher Should Know. Boston: Heinle and Heinle Publishers.

Oxford, R. \& Crookall, D. (1990). Vocabulary Learning: A Critical Analysis of Techniques. TESL Canada Journal, 7(2), 9-30.

Plass, J. L., Chun, D. M., Mayer, R. E. \& Leutner, D. (1998). Supporting Visual and Verbal Learning Preferences in a Second Language Multimedia Learning Environment. Journal of Educational Psychology, 90(1), 25-36.

Ridder, I. D. (2002). Visible or Invisible Links: Does the Highlighting of Hyperlinks Affect Incidental Vocabulary Learning, Text Comprehension, and the Reading Process? Language Learning and Technology. 6 (1). Pp. 123-146. Retrieved October 10, 2007, from http://ltt.msu.edu/vol5numl/alseghayer/default.html.

Rupley, W. H., Logan, J. W. \& Nichols, W. D. (1999). Vocabulary Instruction in a Balanced Reading Program. The Reading Teacher, 52(4), 336-346.

Schneider, V. I., Healy, A. F. \& Bourne, L. E. (2002). What Is Learned under Difficult Conditions Is Hard to Forget: Contextual Interference Effects in Foreign Vocabulary Acquisition, Retention, and Transfer. Journal of Memory and Language 46, 419-440.

Scott, V. M. (1997). Exploring the Link between Teaching and Technology: An Approach to TA Development. In Muyskens, J. A. (ed), New Ways of Learning and Teaching: Focus on Technology and Foreign Language Education. (Report No. FL 027910) (ERIC Document Reproduction Service No. ED482490).

Stoller, F. L. \& Grabe, W. (1997). Reading and Vocabulary Development in a Second Language: A Case Study. In J. Coady, and T. Huckin (Eds.), Second Language Vocabulary Acquisition (pp. 98-124). Cambridge: Cambridge University Press.

Terrell, T. (1986). Acquisition in the Natural Approach: The Binding/access Framework. The Modern Language Journal, 70(3), 213-227.

Tsou, W, wang, W \& Tzeng, Y, (2006). Applying a Multimedia Storytelling Website in Foreign Language Learning. Computers and Education, 47(1), 17 - 28.

Underwood, J. (1989). HyperCard and Interactive Video. CALICO, 6 (3), 7-20.

Willets, K. (1992). Technology and Second Language Learning. (ERIC Document Reproduction Service No. ED350883). Eric Digest. 
Table1. Descriptive Statistics on Participants' Performances in Vocabulary Test

\begin{tabular}{lccc}
\hline & $\begin{array}{c}\text { Group 1: } \\
\text { Text }\end{array}$ & $\begin{array}{c}\text { Group 2: } \\
\text { Picture annotation }\end{array}$ & $\begin{array}{c}\text { Group 3: } \\
\text { Movie annotation }\end{array}$ \\
\hline Participants & 23 & 23 & 23 \\
\hline Number of Items & 30 & 30 & 30 \\
\hline Mean & 21.39 & 24.17 & 26.30 \\
\hline SD & 5.31 & 4.91 & 4.04 \\
\hline Minimum & 12 & 15 & 18 \\
\hline Maximum & 30 & 30 & 30 \\
\hline
\end{tabular}

Table 1 indicates the three groups of participants' performances in the vocabulary test.

As can be seen from the table, the performance of group three, the one receiving reading comprehension texts together with movie clips, was better than the other two groups. The mean score of the first group, the one receiving only reading texts, was the lowest among the all. This reveals that this group's performance on the test was the weakest.

Table 2. ANOVA for the Performance of the Three Groups on Vocabulary Test

\begin{tabular}{lccccc}
\hline Source of variance & Sum of Squares & d.f. & Mean Square & F & Sig. \\
\hline Between groups & 279.217 & 2 & 139.609 & 6.104 & .004 \\
\hline Within groups & 1509.652 & 66 & 22.874 & & \\
\hline Total & 1788.870 & 68 & & &
\end{tabular}

Table 2 indicates the results of the ANOVA run for the data collected.

As the results of the ANOVA shown in the above table indicate, the difference between the mean scores of these three groups is significant $(\mathrm{Sig}=.004, \mathrm{p}<.05)$. This can mean that, the difference is caused by the treatment rather than by chance. In other words, the types of annotation accompanied by reading comprehension texts have caused significant differences in the performances of these groups in the vocabulary test, i.e. the participants have grasped more words and have had better retention. 